\title{
基于 PDCA 的高校教学档案管理的创新与实践
}

\section{Innovation and Practice of College Teaching Archives Management Based on PDCA}

肖乃瑶 赵明雨 张荵

\author{
Naiyao Xiao Mingyu Zhao Rui Zhang
}

沈阳工学院

中国·辽宁 抚顺 113122

Shenyang Institute of Technology,

Liaoning, Fushun, 113122, China
【摘 要】高校档案室的建设及档案的规范化管理是高等院校的核心工作。论文结合沈阳 工学院能源学院的档案工作实际, 以 PDCA 视角对该校教学档案管理展开创新和实践,进 而为专业建设、教学管理以及合格评估提供重要基础和依据。

【Abstract】The construction of college record office and the standardized management of archives are the core tasks of colleges and universities. This paper combines the actual work of the archives of the School of Energy of Shenyang Institute of Technology, and starts to innovate and practice the teaching archives management from the perspective of PDCA, and then provides an important basis and foundation for professional construction, teaching management and conformity assessment.

【关键词】PDCA; 档案管理;创新与实践;

【Keywords】PDCA; archives management; innovation and practice

【DOI】10.36012/sde.v2i4.1865

\section{1 引言}

教学档案是在教学过程中产生的有价值的各类文件资 料,其来源广泛,形式多样, 内容气杂, 因此在教学档案管理过 程中容易出现收集难、整理乱、利用低等问题。本文针对沈阳 工学院能源与水利学院的教学档案管理工作的现状及存在的 问题,通过 PDCA 循环思维结合到教学档案管理工作中, 以创 新的思路加强了教学档案管理工作的规范化。

\section{PDCA 管理的基本概念}

PDCA 管理是由美国著名管理学家戴明提出的, 被广泛 应用于各种管理工作中,他能使任何一项活动有效进行, 是一 种逻辑性非常强的工作程序。它包含四个阶段: $\mathrm{P}(\mathrm{Plan})$ 一计 划、 $\mathrm{D}(\mathrm{Do})$ )一执行、 $\mathrm{C}($ Check ) 一检查、 $\mathrm{A}(\mathrm{Act})$ 一行动(或处理)。 首先, 通过对现状进行分析, 找出存在的问题, 然后制订相应 的计划。其次, 执行计划。再次,检查计划执行的效果, 分清对 错, 发现问题。最后, 总结执行中成功的经验, 并转化为标准, 便于今后工作时遵循, 同时总结不成功的部分, 将没有得到解 决的问题放到下一个 PDCA 管理中, 周而复始地发现问题、解 决问题。它适用于各类组织、各个环节的管理。

\section{3 高校档案管理的创新与实践——以沈} 阳工学院能源与水利学院的实际情况为例

\section{1 高校教学档案管理存在的问题及创新的意义}

3.1.1 高校教学档案管理存在的问题

高校教学档案管理存在的问题:场地设施简陃; 教学档案 管理缺乏专业管理人员; 教学档案管理缺乏规范性; 教学档案 存放杂乱无章。

\subsection{2 高校教学档案管理创新的意义}

高校教学档案能够真实地记录一所院校教学管理及教学 执行的全过程, 关系到学校教学质量, 最终影响人才培养质量 和学校发展, 所以针对以上问题, 高校教学档案管理创新势在 必行。

\section{2 高校教学档案 PDCA 管理}

针对以上总结的高校教学档案管理存在的问题, 本文将 PDCA 管理思维结合到档案管理工作中, 完善了能源与水利 学院的教学档案管理工作,具体的基于 PDCA 管理措施如下。

\section{2 .1 计划}

从档案室和档案存放的设计入手, 彻底改善档案室的环 境及档案摆放规则; 其次利用流程图明确了教学副院长、教学 
秘书教师及借阅人在档案管理工作中的工作内容以及流程, 使得每一项工作有条不紊地进行。

\section{2 .2 执行}

档案室作为教学材料存储的载体, 必须空间足够大, 安全性 高, 并且在格局规划上有较为清晰的布置, 进而促进教学档案管 理的系统性和规范性,能源与水利学院档案室如图 1 所示。

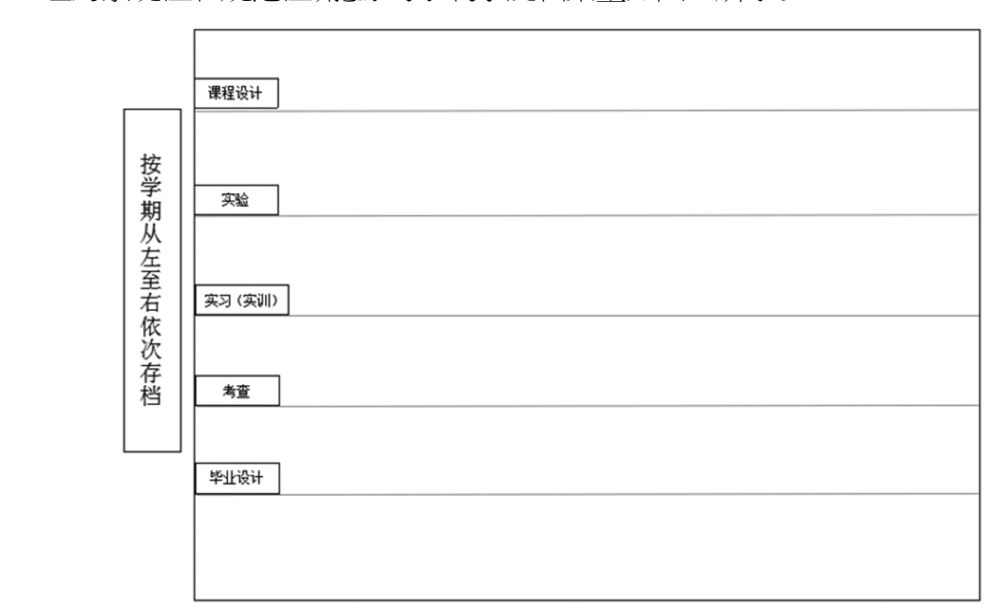

a 档案室主视图

图 1 档案室的设计图
践, 使得教学管理过程明确清晰, 经过半个学期的实践,管理 效果良好, 但仍然有些地方需要提升和改进, 例如, 在每学期 教学存档过程中, 档案管理人员不能够完全确定各教研室存 档的教学材料是否完整齐全, 其次就是教学材料存档后, 依旧 有部分材料存在规范性的问题。

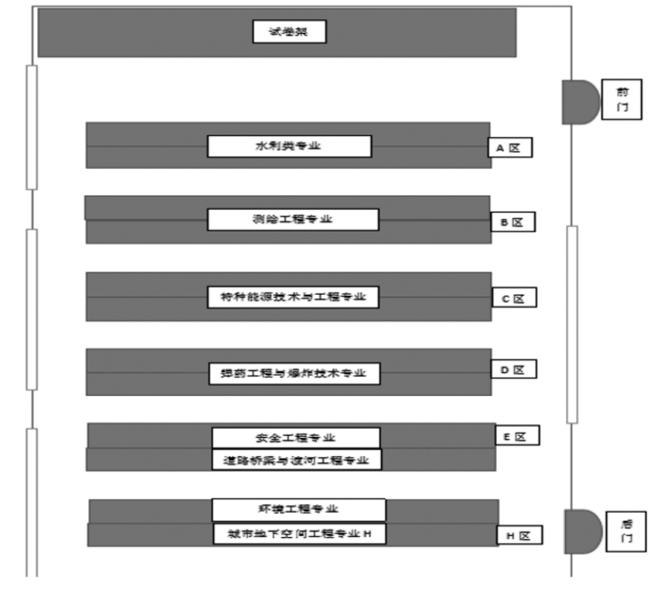

b 档案室俯视图
为了完善教学档案管理工作的过程管理档案管理, 明确 在教学档案管理工作中各环节各位负责人的工作内容, 一个 清晰的工作流程图是至关重要的。教学档案管理流程图如 图 2 所示。

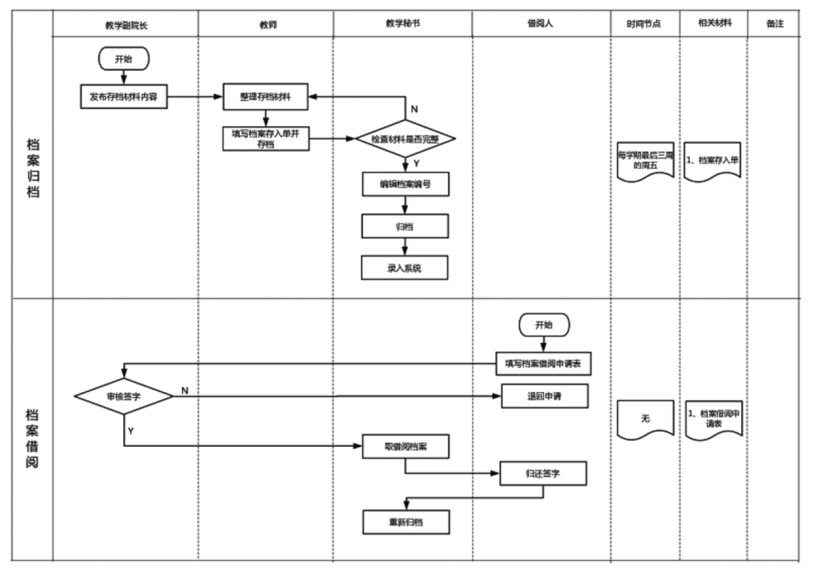

图 2 教学档案管理流程图

为了使档案存放的整齐不乱, 能源与水利学院制作统一 的牛皮纸附在档案的外侧, 使教学档案标准化; 为了能更快速 地查找所需档案, 能源与水利学院制作的档案一览表, 使得教 学档案管理系统化。

\section{2 .3 检查}

能源与水利学院通过以上对教学档案管理的创新与实
3.2 .4 完善

为了进一步完善能源与水利学院教学档案管理工作, 在 下一个 PDCA 循环中能源与水利学院将教学计划深入结合到 教学档案管理工作中, 使教学材料完整齐全, 并且在档案存人 档案室之前, 增加教师互查存档材料过程, 以便保证存档资料 的准确度, 同时引进更为先进的科学手段到教学档案管理工 作, 增强档案管理效率, 为专业建设、教学管理以及合格评估 提供重要基础和依据。

\section{4 总结}

教学档案作为教学过程中留存的重要作证材料, 不仅在本 科院校合格评估中具有重要作用, 在今后的院校可持续发展中 同样具有重要作用。随着社会的发展, 教育事业不断蓬勃发展, 教 学档案管理作为高校发展的重要组成部分, 也应该不断创新并 且与时俱进,进而更好地提高高校的办学质量和教学管理水平。

\section{参考文献}

[1]夏陶.浅谈应用型本科院校二级学院的教学档案管理[J].文教 资料,2018,798(24):205-206.

[2]金晓鹏.浅析高校教学档案规范化管理中存在的问题及对策 [J].档案,2018,300(11):59-61.

[3]孔文.高校二级单位教学档案管理探讨 [J].兰台内外,2014(2): 68. 